\title{
AN ALGORITHM TO DETERMINING THE GEAR EFFICIENCY TO A SIMPLE PLANETARY TRAIN
}

Florian Ion Tiberiu Petrescu Bucharest Polytechnic University, Romania

E-mail: petrescuflorian@yahoo.com

Relly Victoria Virgil Petrescu Bucharest Polytechnic University, Romania E-mail: petrescuvictoria@yahoo.com

Submission: 10/20/2015

Revision: 10/30/2015 Accept: 11/28/2018

\section{ABSTRACT}

The paper presents an original algorithm composed by authors in order to determine through exact calculations the efficiency value of a simple planetary mechanism, increasingly used in aerospace, robotics, mechatronics, machine building, and various automation. The calculation program is written in excel and for its simple automation four sign-type switches, are used plus or minus 1 , and a logic function for checking the status and choosing the corresponding value. In this way, the program is generalized to be used for any type of simple planetary mechanism for the purpose of accurately determining its yield.

Keywords: Computer science; Calculation program; Automation; Logic function 
DOI: 10.14807/ijmp.v10i5.392

\section{INTRODUCTION}

A mechanical transmission is a mechanical device used for the purpose of transmitting movement from one side to the other usually by means of a mechanism having elements and kinematic couplings. The mechanical transmission must adjust the torque and speed between the drive (input) and traction element (s) (CAO et al., 2013).

Motion transmission is one of the most common functions of general mechanical components, mechanical devices designed to replace the human hand (GARCIA et al., 2007).

According to the mechanisms, the transmission is dimensioned according to considerations related to (LEE, 2013):

- Position of a part of the mechanism

- The desired movement

- Force or torque

- The power

Epicyclic transmission is a mechanical transmission device. It has the particularity of having two degrees of mobility, such as a differential, that is, the association of three trees at different rotational speeds with a mathematical relationship: The speeds of two trees are thus correlated to the third.

These trains are often used to reduce speed due to the high reduction ratios that this configuration allows to be uniformly compact with a single wheel. These mechanisms are especially found in automatic gearboxes, the Toyota Hybrid Synergy Drive, the integrated bicycle knobs, the electric motors on wheels, the winch and the double-robotic clutch.

The term epicycloid comes from the trajectory that follows an epicicloid from a point of the satellites observed on the inner planetary. However, a hypocicloid is observed if the motion reference is external to the planetary, often fixed in the reducers. This corresponds exactly to what the observer observes when viewing a satellite. 
Configuration adopted in the machine differential. The axis of rotation of the satellites (often in pairs) is perpendicular to the planet. As a result, the gears are conical.

If the satellite stays fixed on the planetary gears, the two planets have the same rotation speed. When planets move at different speeds, the satellite rotates while transmitting power:

- Applications

- Blaise Pascal computing machine: Pascaline

- Integrated blade for bicycle tools

- Differences in the car

- Most automatic automatic gearboxes and more mechanical gearboxes (for example, the Ford T model)

- The electro-mechanical transmission of the Toyota Prius hybrid and, in general, Toyota and Lexus (the HSD system)

- Frequency multipliers in wind turbines

- Garden tools (e.g. plant crushers)

- Helicopters

It is mainly used for epicyclic trains. They are present in automatic gearboxes and in many gearboxes coupled to electric motors. They appear in the same catalogs as the latter. Their geometry provides a coaxial output shaft with the input shaft, which facilitates its implementation. Finally, they have a great ability to reduce speed. In general, three satellites are placed on the satellite carrier. Thus, the forces in the gear are not taken over by the bearings. As a result, these gearboxes are very suitable for high torque transmission.

These devices are sometimes used as multipliers, as with wind turbines. Again, here is their compactness and the absence of the radial force induced in the camps of incoming and outgoing trees that justify their use.

From the simplest train (Type I), mobility is eliminated by fastening the outer gear, also called the crown. 
DOI: 10.14807/ijmp.v10i5.392

The input tree, while rotating, forces the satellite to roll inside the crown. In her movement, she drives the satellite door as if it were a maneuver. The planetary support is the output shaft of the device. In this configuration, the output rotates in the same direction and slower than the input.

Planetary transmissions have a number of advantages compared to fixed axle transmission. Under similar operating conditions, planetary transmissions operate longer and produce less noise compared to a fixed shaft transmission [1-6]. The gearboxes are generally used to reduce the rotational speed of the lucrative machine, such as a turbine, relative to the engine speed used. Easy to achieve performance up to $110 \mathrm{MW}$ or turbine rotation speeds of approximately $60,000 \mathrm{rpm}$. Parallel shaft transmission mechanisms are typically used in these applications. However, some manufacturers of packaging and generator manufacturers use planetary gears for gas and steam turbine systems. Most planetary gear manufacturers are located in Europe and the United States. Generally, the synthesis of classical planetary mechanisms is based on the kinematic relations given by formula 1 (ANDERSON; LOEWENTHAL, 1986; PETRESCU, 2019), considering mainly the transmission ratio achieved. The most commonly used model is the differential planetary mechanism shown in Figure 1 with two degrees of freedom. Formula 1 is obtained through the well-known Willis relationship.

$$
i_{H 3}^{1}=\frac{1}{i_{3 H}^{1}}=\frac{1}{1-i_{31}^{H}}=\frac{1}{1-\frac{1}{i_{13}^{H}}}
$$

where, $i_{13}^{H}$ is the ratio of transmission input output, corresponding to the mechanism with fixed axis (when the planetary carrier $\mathrm{H}$ is fixed) and is determined in function of the cinematic schematic of planetary gear used.

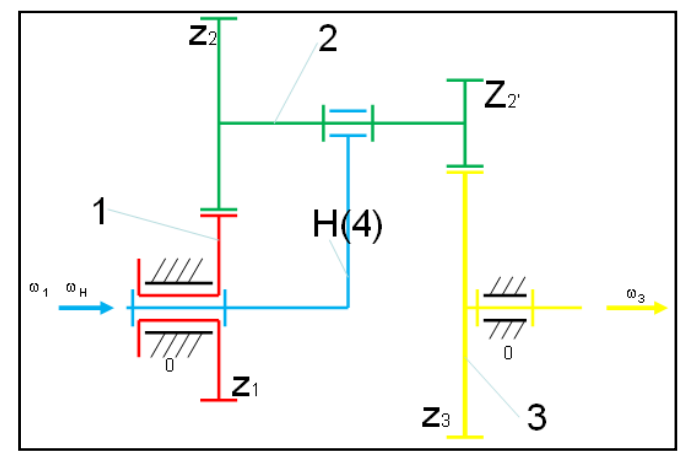

Figure 1: Kinematic schematic of a differential planetary mechanism $(M=2)$ 
In general, planetary mechanisms are less synthesized based on their mechanical efficiency developed during operation, although this is basically the main engineering criterion of performance.

Even when considering the efficiency criterion, the determination of the planetary yield is made only with approximate relationships (MARTIN, 1981; ANTONESCU, 1979; PELECUDI et al., 1985; PENNESTRI; FREUDENSTEIN, 1993) or with a particular character (not generalized) del (CASTILLO, 2002; CHO et al., 2006). This paper aims to determine the real efficiency of planetary trains by means of an exact, generalized calculation algorithm that takes into account the efficiency of the mechanism determined by an exact original method, the algorithm being also an original one (PETRESCU; PETRESCU, 2011; PETRESCU, 2012; PETRESCU et al., 2016).

\section{MATERIALS AND METHODS}

Classically, the synthesis of planetary mechanisms is generally achieved through kinematic relations, especially taking into account the ratio of transmission made from input to output. The most commonly used model is the differential planetary mechanism as shown in Figure 1.

Generally, in practice, simple planetary mechanisms with only one degree of mobility are used, except for the differential mechanism. For the differential mechanism to achieve a single degree of mobility, remaining in use with a single input and a unique output, it is necessary to reduce the mobility of the two to one mechanism, a reduction that can be achieved by connecting in series or parallel two or several planetary mechanisms by linking to fixed axle mechanisms or by immobilizing one of its movable elements; element 1 in the case shown in Figure 2 (in which case the wheel 1 is identified with the fixed element 0 ).

The entrance to the simple planetary mechanism shown in Figure 2 is made by the planetary support $(\mathrm{H})$, and the output is made by means of the movable kinematic element (3), the wheel (3). The kinematic ratio between input-output $(\mathrm{H}-3)$ can be written as shown in relation $1 ; i_{13}^{H}$ is the ratio of transmission input output of the model in Figure 2 and is determined by relation 2, depending on the number of teeth of wheels $1,2,2$ ' and 3 : 


$$
i_{13}^{H}=\frac{Z_{2}}{z_{1}} \cdot \frac{z_{3}}{Z_{2^{\prime}}}
$$

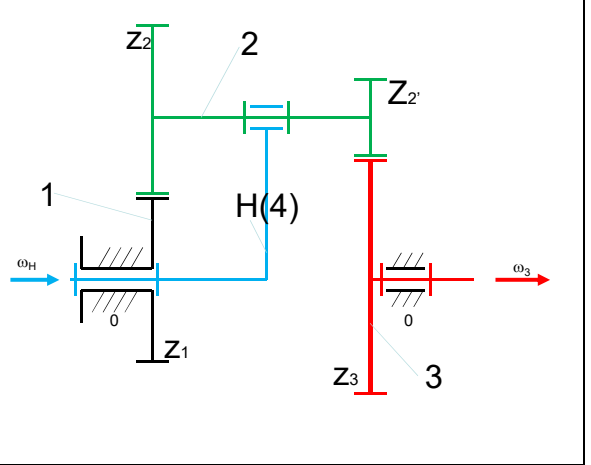

Figure 2: Kinematic schema of a simple planetary mechanism $(\mathrm{M}=1)$

For the stiffening of the various kinematic planetary systems represented in figure 3 , where the input is made by the planetary support $(\mathrm{H})$ and the output is obtained by the final element (f), the initial element that is usually immobilized will be used for kinematic calculations in the generalized relations 1 and 2; thus the relation 1 takes the general form 3 and the relation 2 is written in one of the custom 4 forms for each separately presented scheme used; where $i$ it becomes 1 and $f$ takes the value 3 or 4 as the case (PETRESCU AND PETRESCU, 2011; PETRESCU, 2012; PETRESCU et al., 2016).

$$
\left\{\begin{array}{l}
i_{13}^{H}=\frac{\omega_{1}-\omega_{H}}{\omega_{3}-\omega_{H}} \equiv \frac{z_{2}}{z_{1}} \cdot \frac{z_{3}}{z_{2}} \\
\frac{z_{2}}{z_{1}} \cdot \frac{z_{3}}{z_{2}}=\frac{\frac{\omega_{1}}{\omega_{H}}-\frac{\omega_{H}}{\omega_{H}}}{\frac{\omega_{3}}{\omega_{H}}-\frac{\omega_{H}}{\omega_{H}}} \\
i_{13}^{H}=\frac{z_{2} \cdot z_{3}}{z_{1} \cdot z_{2}}=\frac{0-1}{\frac{\omega_{3}}{\omega_{H}}-1}=\frac{1}{1-i_{3 H}}=\frac{1}{1-\frac{1}{i_{H 3}^{1}}} \Rightarrow \\
\Rightarrow i_{H 3}^{1}=\frac{1}{1-\frac{1}{i_{13}^{H}}}
\end{array}\right.
$$


ISSN: 2236-269X

DOI: 10.14807/ijmp.v10i5.392

$$
i_{H f}^{i}=\frac{1}{i_{f H}^{i}}=\frac{1}{1-i_{f i}^{H}}=\frac{1}{1-\frac{1}{i_{i f}^{H}}}
$$

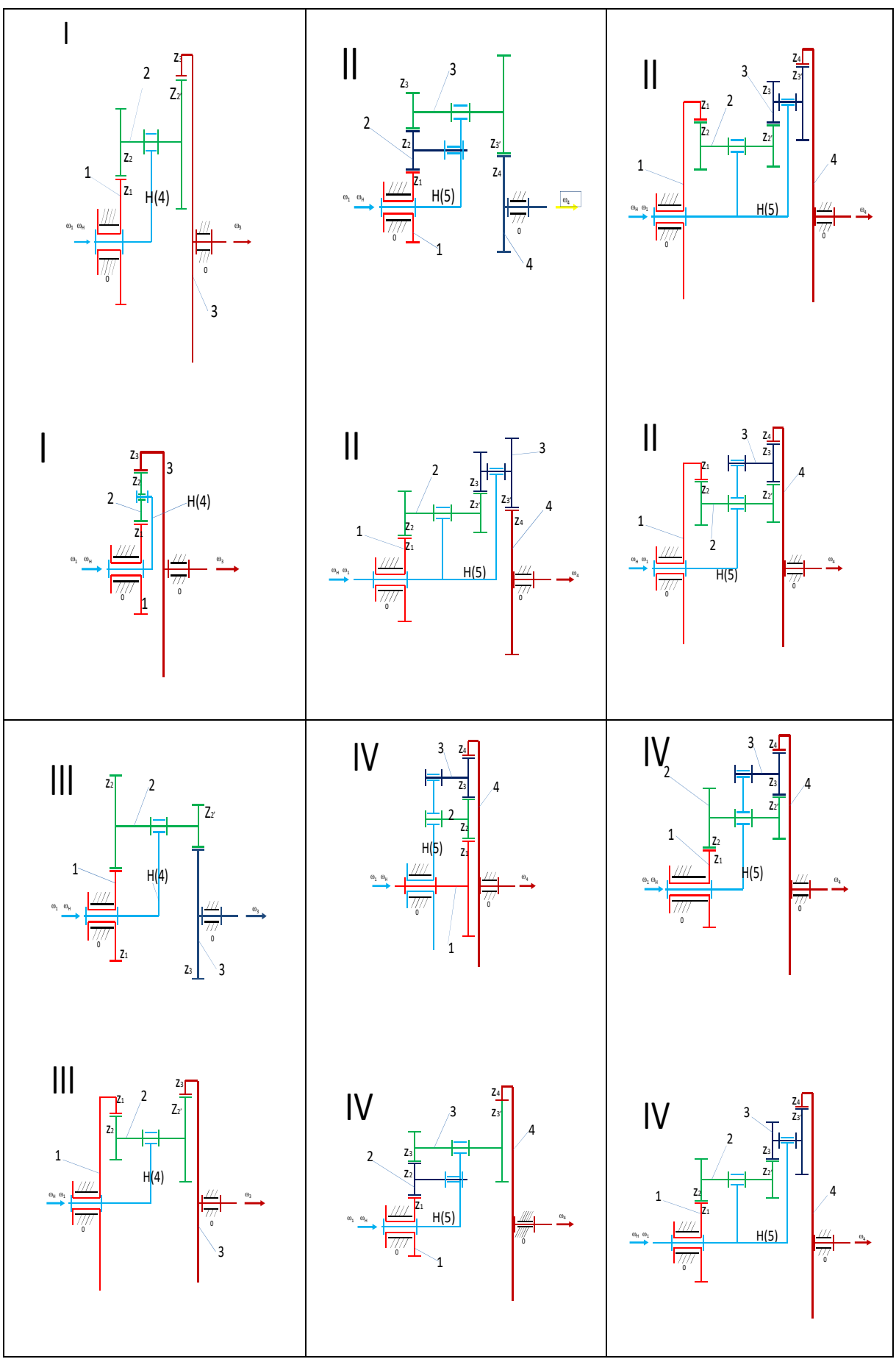

Figure 3: Planetary systems 




For the ratio between the input and output of the transmission of the models in Figure 3 , one of the system 5 relations is chosen, according to the situation used.

For a normally planetary system (Figure 2) the mechanical efficiency can be determined based on system 5 , which shows that the power between input-output is conserve. With Willis one determines $\omega_{3}$. It uses then the conservation of power between input-output for a simple planetary gear apparently fixed axis (1-input, 3output). For calculating the efficiency of the simple planetary mechanism, the original relationships given by system 6 are used. 
DOI: 10.14807/ijmp.v10i5.392

$$
\begin{aligned}
& \int\left(i_{13}^{H}=\frac{\omega_{1}-\omega_{H}}{\omega_{3}-\omega_{H}} \Rightarrow \omega_{3}-\omega_{H}=\frac{\omega_{1}-\omega_{H}}{i_{13}^{H}} \Rightarrow\right. \\
& \left\{\omega_{3}=\frac{\omega_{H} \cdot\left(i_{13}^{H}-1\right)+\omega_{1}}{i_{13}^{H}} \text { and with } \omega_{1}=0 \Rightarrow\right. \\
& i_{13}^{H}=\frac{z_{2} \cdot z_{3}}{Z_{1} \cdot z_{2}} \quad \Rightarrow \omega_{3}=\frac{\omega_{H} \cdot\left(i_{13}^{H}-1\right)}{i_{13}^{H}} \\
& P_{i}+P_{o}=0 \\
& \left(M_{1} \cdot \omega_{1}^{*} \cdot\left(\eta_{13}^{H}\right)^{X}+M_{3} \cdot \omega_{3}^{*}=0 \Rightarrow\right. \\
& \eta_{13}^{x}=\frac{-M_{3} \cdot \omega_{3}^{*}}{M_{1} \cdot \omega_{1}^{*}} \Rightarrow \eta_{13}^{x}=\frac{-M_{3}}{M_{1}} \cdot \frac{\omega_{3}-\omega_{H}}{\omega_{1}-\omega_{H}} \Rightarrow \\
& \Rightarrow \eta_{13}^{x}=\frac{-M_{3}}{M_{1}} \cdot \frac{\omega_{3}-\omega_{H}}{-\omega_{H}} \Rightarrow \\
& \eta_{13}^{x}=\frac{-M_{3}}{M_{1}} \cdot \frac{1}{i_{13}^{H}} \Rightarrow M_{1}=\frac{-M_{3}}{\eta_{13}^{X} \cdot i_{13}^{H}} \\
& M_{1}+M_{3}+M_{H}=0 \Rightarrow M_{H}=-\left(M_{1}+M_{3}\right) \\
& =-\left(\frac{-M_{3}}{\eta_{13}^{X} \cdot i_{13}^{H}}+M_{3}\right)=-M_{3} \cdot \frac{\eta_{13}^{X} \cdot i_{13}^{H}-1}{\eta_{13}^{X} \cdot i_{13}^{H}} \\
& M_{H} \cdot \omega_{H} \cdot \eta_{H 3}^{1}+M_{3} \cdot \omega_{3}=0 \Rightarrow \eta_{H 3}^{1}=\frac{-M_{3} \cdot \omega_{3}}{M_{H} \cdot \omega_{H}} \Rightarrow \\
& \eta_{H 3}=\frac{-M_{3} \cdot \omega_{3} \cdot \eta_{13}^{X} \cdot i_{13}^{H}}{-M_{3} \cdot\left(\eta_{13}^{X} \cdot i_{13}^{H}-1\right) \cdot \omega_{H}} \Rightarrow \\
& \Rightarrow \eta_{H 3}=\frac{\left(\omega_{H}-\frac{\omega_{H}}{i_{13}^{H}}\right) \cdot \eta_{13}^{x} \cdot i_{13}^{H}}{\left(\eta_{13}^{x} \cdot i_{13}^{H}-1\right) \cdot \omega_{H}} \Rightarrow \\
& \eta_{H 3}=\frac{\left(i_{13}^{H}-1\right) \cdot \eta_{13}^{x}}{\left(\eta_{13}^{x} \cdot i_{13}^{H}-1\right)} \Rightarrow \eta_{H 3}=\eta_{13}^{X} \cdot \frac{\left(i_{13}^{H}-1\right)}{\left(\eta_{13}^{x} \cdot i_{13}^{H}-1\right)} \\
& \left\{x=1 \text { for } i_{13}^{H} \leq 1 ; i_{13}^{H}-1 \leq 0\right. \\
& x=-1 \text { for } i_{13}^{H}>1 \quad i_{13}^{H}-1>0
\end{aligned}
$$

It also uses the auxiliary original calculation relationships 7-9 (PETRESCU; PETRESCU, 2014 a-b).

$$
\eta_{m}=\frac{z_{1}^{2} \cdot \cos ^{2} \beta}{z_{1}^{2} \cdot\left(\operatorname{tg}^{2} \alpha_{0}+\cos ^{2} \beta\right)+\frac{2}{3} \pi^{2} \cdot \cos ^{4} \beta \cdot(\varepsilon-1) \cdot(2 \varepsilon-1) \pm 2 \pi \cdot \operatorname{tg}_{0} \cdot z_{1} \cdot \cos ^{2} \beta \cdot(\varepsilon-1)}
$$




$$
\begin{aligned}
& \varepsilon^{a . e .}=\frac{1+\operatorname{tg}^{2} \beta}{2 \cdot \pi} \cdot\left\{\sqrt{\left[\left(z_{1}+2 \cdot \cos \beta\right) \cdot \operatorname{tg} \alpha_{0}\right]^{2}+4 \cdot \cos ^{3} \beta \cdot\left(z_{1}+\cos \beta\right)}+\right. \\
& \left.+\sqrt{\left[\left(z_{2}+2 \cdot \cos \beta\right) \cdot \operatorname{tg} \alpha_{0}\right]^{2}+4 \cdot \cos ^{3} \beta \cdot\left(z_{2}+\cos \beta\right)}-\left(z_{1}+z_{2}\right) \cdot \operatorname{tg} \alpha_{0}\right\} \\
& \varepsilon^{a . i .}=\frac{1+\operatorname{tg}^{2} \beta}{2 \cdot \pi} \cdot\left\{\sqrt{\left[\left(z_{e}+2 \cdot \cos \beta\right) \cdot \operatorname{tg} \alpha_{0}\right]^{2}+4 \cdot \cos ^{3} \beta \cdot\left(z_{e}+\cos \beta\right)}-\right. \\
& \left.-\sqrt{\left[\left(z_{i}-2 \cdot \cos \beta\right) \cdot \operatorname{tg} \alpha_{0}\right]^{2}-4 \cdot \cos ^{3} \beta \cdot\left(z_{i}-\cos \beta\right)}-\left(z_{e}-z_{i}\right) \cdot \operatorname{tg} \alpha_{0}\right\}
\end{aligned}
$$

\section{RESULTS AND DISCUSSION}

To calculate the yield of a simple planetary mechanism using original

\begin{tabular}{|c|c|c|}
\hline & $\bar{A}$ & B \\
\hline 1 & $\square$ H3 & =B36 \\
\hline 2 & $\mathbf{i}_{13 \mathrm{H}}$ & $=$ B33 \\
\hline 3 & $x$ & $=I F(B 33<=1,1,-1)$ \\
\hline 4 & $\varphi[\mathrm{deg}]$ & 400 \\
\hline 5 & $\mathrm{z}_{1}$ & 20 \\
\hline 6 & $\mathrm{z}_{2}$ & 50 \\
\hline 7 & $\mathrm{Z}_{2^{\prime}}$ & 30 \\
\hline 8 & $\mathrm{Z}_{3}$ & 40 \\
\hline 9 & $\alpha_{012}$ [deg] & $=20-0.01^{*} \mathrm{~B} 4$ \\
\hline 10 & $\alpha_{023}$ [deg] & $=20+0.01^{*} \mathrm{~B} 4$ \\
\hline 11 & $\beta_{12}$ [deg] & $=10+0.05^{*} \mathrm{~B} 4$ \\
\hline 12 & $\beta_{23}[\mathrm{deg}]$ & $=10+0.06 * B 4$ \\
\hline 13 & $\operatorname{sign} z_{1}$ & 1 \\
\hline 14 & $\operatorname{sign} Z_{2^{\prime}}$ & 1 \\
\hline 15 & Sign 12 & 1 \\
\hline 16 & Sign 23 & 1 \\
\hline 17 & & \\
\hline 18 & $\alpha_{012}$ [rad] & $=\mathrm{B} 9 * \mathrm{PI}() / 180$ \\
\hline 19 & $\alpha_{023}$ [rad] & $=\mathrm{B} 10^{*} \mathrm{PI}() / 180$ \\
\hline 20 & $\beta_{12}[\mathrm{rad}]$ & $=\mathrm{B} 11^{*} \mathrm{PI}() / 180$ \\
\hline 21 & $\beta_{23}$ [rad] & $=\mathrm{B} 12^{*} \mathrm{PI}() / 180$ \\
\hline 22 & $\cos \left(\beta_{12}\right)$ & $=\cos (\mathrm{B} 20)$ \\
\hline 23 & $\tan \left(\alpha_{012}\right)$ & $=$ TAN $(B 18)$ \\
\hline 24 & $\tan \left(\beta_{12}\right)$ & $=\mathrm{TAN}(\mathrm{B} 20)$ \\
\hline 25 & & $=\left(1+\mathrm{B} 24^{\wedge} 2\right) / 2 / \mathrm{PI}()^{\star}\left(\mathrm{SQRT}\left(\left(\left(\mathrm{B} 5+2^{*} \mathrm{~B} 22\right)^{\star} \mathrm{B} 23\right)^{\wedge} 2+4^{*} \mathrm{~B} 22^{\wedge} 3^{*}(\mathrm{~B} 5+\mathrm{B} 22)\right)+\mathrm{B} 15^{\star} \mathrm{SQRT}(\right.$ \\
\hline 26 & $\square 12$ & $\begin{array}{l}\left.\left.\left(\left(\mathrm{B} 6+\mathrm{B} 15^{*} 2^{*} \mathrm{~B} 22\right)^{*} \mathrm{~B} 23\right)^{\wedge} 2+\mathrm{B} 15^{*} 4^{\star} \mathrm{B} 22^{\wedge} 3^{*}\left(\mathrm{~B} 6+\mathrm{B} 15^{*} \mathrm{~B} 22\right)\right)-\left(\mathrm{B} 5+\mathrm{B} 15^{*} \mathrm{~B} 6\right)^{\star} \mathrm{B} 23\right) \\
=\mathrm{B} 5^{\wedge} 2^{\star} \mathrm{B} 22^{\wedge} 2 /\left(\mathrm{B} 5^{\wedge} 2^{*}\left(\mathrm{~B} 23^{\wedge} 2+\mathrm{B} 22^{\wedge} 2\right)+2 / 3^{\star} \mathrm{P} \mid()^{\wedge} 2^{\star} \mathrm{B} 22^{\wedge} 4^{\star}(\mathrm{B} 25-1)^{\star}\left(2^{*} \mathrm{~B} 25-\right.\right.\end{array}$ \\
\hline & $\square 12$ & 1)+B13*2* $\left.\mathrm{PI}()^{*} \mathrm{~B} 23^{*} \mathrm{~B} 5^{*} \mathrm{~B} 22^{\wedge} 2^{*}(\mathrm{~B} 25-1)\right)$ \\
\hline 27 & $\cos \left(\beta_{23}\right)$ & $=\operatorname{COS}(\mathrm{B} 21)$ \\
\hline 28 & $\tan \left(\alpha_{023}\right)$ & $=\mathrm{TAN}(\mathrm{B} 19)$ \\
\hline 29 & $\tan \left(\beta_{23}\right)$ & $=\mathrm{TAN}(\mathrm{B} 21)$ \\
\hline 30 & $\lceil 23$ & $=\left(1+\mathrm{B} 29^{\wedge} 2\right) / 2 / \mathrm{PI}()^{*}\left(\mathrm{SQRT}\left(\left(\left(\mathrm{B} 7+2^{*} \mathrm{~B} 27\right)^{*} \mathrm{~B} 28\right)^{\wedge} 2+4^{*} \mathrm{~B} 27^{\wedge} 3^{*}(\mathrm{~B} 7+\mathrm{B} 27)\right)+\mathrm{B} 16^{*} \mathrm{SQRT}(\right.$ \\
\hline & $\square 23$ & $\left(\left(\mathrm{~B} 8+\mathrm{B} 16^{*} 2^{*} \mathrm{~B} 21\right)\right.$ \\
\hline
\end{tabular}
relationships $6-9$, one writes an original calculation algorithm using the familiar excel program shown below in the table 1 .

Table 1: An original calculation algorithm written in excel 
INDEPENDENT JOURNAL OF MANAGEMENT \& PRODUCTION (IJM\&P)

http://Www.ijmp.jor.br

V. 10, n. 5, September-October 2019

ISSN: 2236-269X

DOI: 10.14807/ijmp.v10i5.392

$=\mathrm{B} 7^{\wedge} 2^{*} \mathrm{~B} 27^{\wedge} 2 /\left(\mathrm{B} 7^{\wedge} 2^{*}\left(\mathrm{~B} 28^{\wedge} 2+\mathrm{B} 27^{\wedge} 2\right)+2 / 3^{*} \mathrm{PI}()^{\wedge} 2^{*} \mathrm{~B} 27^{\wedge} 4^{*}(\mathrm{~B} 30-1)^{*}\left(2^{*} \mathrm{~B} 30-\right.\right.$

$32 \square 23$

1) $\left.+\mathrm{B} 14^{*} 2^{*} \mathrm{PI}()^{*} \mathrm{~B} 28^{*} \mathrm{~B} 7^{*} \mathrm{~B} 27^{\wedge} 2^{*}(\mathrm{~B} 30-1)\right)$

$33 \quad \mathrm{i}_{13 \mathrm{H}} \quad=\mathrm{B} 6{ }^{*} \mathrm{~B} 8 / \mathrm{B} 5 / \mathrm{B} 7$

$34 \square \square 3 \mathrm{H} \quad=\mathrm{B} 26^{*} \mathrm{~B} 31$

$35 \times \quad=I F(B 33<=1,1,-1)$

$36 \square \mathrm{H} 3 \quad=\mathrm{B} 34^{\wedge} \mathrm{B} 35^{*}(1-\mathrm{B} 33) /\left(1-\mathrm{B} 34^{\wedge} \mathrm{B} 35^{*} \mathrm{~B} 33\right)$

The tooth mark in lines $13-14$, take 1 for outer teeth, and -1 for inner teeth.

Gear markings in lines 15-16, are 1 for external gearing and -1 for internal gearing.

In system 6 there is an $x$ exponent that can take the value +1 or -1 . It is identified in the computing program through a logical function (see the line 35).

Next, some examples of calculation are presented in the four Figure 4-7. It analyzed the mechanism model shown in Figure 2. Input-output gear ratio achieved, iH3, is: 11 (Figure 4), -10 (Figure 5), 5 (Figure 6), -0.2 (Figure 7). On the left side of a Fig. using standard pressure angle of 20 degrees [deg] and the right of every Fig. uses a pressure angle decreased to 10 degrees [deg].

\begin{tabular}{|c|c|c|c|}
\hline$\eta \mathrm{H} 3$ & 0.25622 & $\eta \mathrm{H} 3$ & 0.37708 \\
\hline $\mathrm{i} 13 \mathrm{H}$ & 1.1 & $\mathrm{i} 13 \mathrm{H}$ & 1.1 \\
\hline$x$ & -1 & $x$ & -1 \\
\hline $\mathrm{iH} 3$ & 11 & $\mathrm{iH3}$ & 11 \\
\hline$z 1$ & 42 & $z 1$ & 42 \\
\hline$z 2$ & 42 & $z 2$ & 42 \\
\hline$z 2^{\prime}$ & 40 & $z 2^{\prime}$ & 40 \\
\hline 23 & 44 & $z 3$ & 44 \\
\hline $\begin{array}{l}\text { alfa012 } \\
\text { [deg] }\end{array}$ & 20 & $\begin{array}{l}\text { alfa012 } \\
\text { [deg] }\end{array}$ & 10 \\
\hline $\begin{array}{l}\text { alfa023 } \\
\text { [deg] }\end{array}$ & 20 & $\begin{array}{l}\text { alfa023 } \\
\text { [deg] }\end{array}$ & 10 \\
\hline $\begin{array}{l}\text { beta12 } \\
\text { [deg] }\end{array}$ & 15 & $\begin{array}{l}\text { beta12 } \\
\text { [deg] }\end{array}$ & 15 \\
\hline $\begin{array}{l}\text { beta23 } \\
\text { [deg] }\end{array}$ & 15 & $\begin{array}{l}\text { beta23 } \\
\text { [deg] }\end{array}$ & 15 \\
\hline
\end{tabular}

Figure $4: \mathrm{i}_{13}{ }^{\mathrm{H}}=1.1$

\begin{tabular}{|c|c|c|c|}
\hline$\eta \mathrm{H3}$ & 0.18391 & $\eta \mathrm{H} 3$ & 0.32408 \\
\hline $\mathrm{i} 13 \mathrm{H}$ & 0.90909 & $\mathrm{i} 13 \mathrm{H}$ & 0.90909 \\
\hline$x$ & 1 & $x$ & \\
\hline $\mathrm{iH} 3$ & -10 & $\mathrm{iH} 3$ & -10 \\
\hline$z 1$ & 42 & $z 1$ & 42 \\
\hline$z 2$ & 42 & $z 2$ & 42 \\
\hline$z 2^{\prime}$ & 44 & $z 2^{\prime}$ & 44 \\
\hline 23 & 40 & $z 3$ & 40 \\
\hline $\begin{array}{l}\text { alfa012 } \\
\text { [deg] }\end{array}$ & 20 & $\begin{array}{l}\text { alfa012 } \\
\text { [deg] }\end{array}$ & 10 \\
\hline $\begin{array}{l}\text { alfa023 } \\
\text { [deg] }\end{array}$ & 20 & $\begin{array}{l}\text { alfa023 } \\
\text { [deg] }\end{array}$ & 10 \\
\hline $\begin{array}{l}\text { beta12 } \\
\text { [deg] }\end{array}$ & 15 & $\begin{array}{l}\text { beta12 } \\
\text { [deg] }\end{array}$ & 15 \\
\hline $\begin{array}{l}\text { beta23 } \\
\text { [deg] }\end{array}$ & 15 & $\begin{array}{l}\text { beta23 } \\
\text { [deg] }\end{array}$ & 15 \\
\hline
\end{tabular}

Figure 5: $\mathrm{i}_{13}{ }^{\mathrm{H}}=0.9(09)$ 
DOI: 10.14807/ijmp.v10i5.392

\begin{tabular}{|c|c|c|c|}
\hline$\eta \mathrm{H} 3$ & 0.45429 & $\eta \mathrm{H} 3$ & 0.57698 \\
\hline $\mathrm{i} 13 \mathrm{H}$ & 1.25 & $\mathrm{i} 13 \mathrm{H}$ & 1.25 \\
\hline$x$ & -1 & $x$ & -1 \\
\hline $\mathrm{iH} 3$ & 5 & $\mathrm{iH} 3$ & 5 \\
\hline$z 1$ & 32 & $z 1$ & 32 \\
\hline$z 2$ & 40 & $z 2$ & 40 \\
\hline z2' & 36 & z2' & 36 \\
\hline 23 & 36 & 23 & 36 \\
\hline $\begin{array}{l}\text { alfa012 } \\
\text { [deg] }\end{array}$ & 20 & $\begin{array}{l}\text { alfa012 } \\
\text { [deg] }\end{array}$ & 10 \\
\hline $\begin{array}{l}\text { alfa023 } \\
\text { [deg] }\end{array}$ & 20 & $\begin{array}{l}\text { alfa023 } \\
\text { [deg] }\end{array}$ & 10 \\
\hline $\begin{array}{l}\text { beta12 } \\
{[\text { deg] }}\end{array}$ & 15 & $\begin{array}{l}\text { beta12 } \\
\text { [deg] }\end{array}$ & 15 \\
\hline $\begin{array}{l}\text { beta23 } \\
{[\text { deg] }}\end{array}$ & 15 & $\begin{array}{l}\text { beta23 } \\
\text { [deg] }\end{array}$ & 15 \\
\hline
\end{tabular}

Figure 6: $\mathrm{i}_{13}{ }^{\mathrm{H}}=1.25$

\begin{tabular}{|c|c|c|c|}
\hline$\eta \mathrm{H} 3$ & 0.68961 & $\eta \mathrm{H} 3$ & 0.84792 \\
\hline i13H & 1.6666 & i13H & 1.16666 \\
\hline$x$ & 1 & $x$ & 1 \\
\hline $\mathrm{iH} 3$ & -0.2 & iH3 & -0.2 \\
\hline$z 1$ & 48 & $z 1$ & 48 \\
\hline$z 2$ & 32 & $z 2$ & 32 \\
\hline$z 2^{\prime}$ & 64 & $z 2^{\prime}$ & 64 \\
\hline 23 & 16 & $z 3$ & 16 \\
\hline $\begin{array}{l}\text { alfa012 } \\
\text { [deg] }\end{array}$ & 20 & $\begin{array}{l}\text { alfa012 } \\
\text { [deg] }\end{array}$ & 10 \\
\hline $\begin{array}{l}\text { alfa023 } \\
\text { [deg] }\end{array}$ & 20 & $\begin{array}{l}\text { alfa023 } \\
\text { [deg] }\end{array}$ & 10 \\
\hline $\begin{array}{l}\text { beta12 } \\
\text { [deg] }\end{array}$ & 15 & $\begin{array}{l}\text { beta12 } \\
\text { [deg] }\end{array}$ & 15 \\
\hline $\begin{array}{l}\text { beta23 } \\
\text { [deg] }\end{array}$ & 15 & $\begin{array}{l}\text { beta23 } \\
\text { [deg] }\end{array}$ & 15 \\
\hline
\end{tabular}

Figure $7: \mathrm{i}_{13}{ }^{\mathrm{H}}=1 .(6)$

It was considered for all cases a tilt teeth angle of 15 degrees [deg].

\section{CONCLUSIONS}

The planetary system efficiency given by the original exact presented formula has the great advantage to be determined easy and for any type of simple planetary gear.

By this we have now high precision in any asked case.

Planetary mechanisms have a significant number of advantages over fixed axis transmission. Under similar operating conditions, the planetary transmissions have a longer life and produce less noise compared to a fixed shaft transmission.

The efficiency of the planetary system obtained through the original formula presented has the great advantage of being easily determined and can at the same time be used for any type of simple planetary mechanisms. In other words, the great advantage of this formula is its generality.

A second great advantage of this formula is its precision.

Analyzing the previous calculation examples, it can be noticed that the yield (of a simple planetary gear) increases when the sun gear transmission ratio input-output decreases and also when alfa0 angle is decreased. 
INDEPENDENT JOURNAL OF MANAGEMENT \& PRODUCTION (IJM\&P)

http://Www.ijmp.jor.br

V. 10, n. 5, September-October 2019

ISSN: 2236-269X

DOI: 10.14807/ijmp.v10i5.392

\section{REFERENCES}

ANDERSON, N. E.; S.H. LOEWENTHAL, S. H. (1986) Efficiency of nonstandard and high contact ratio involute spur gears. J. Mech. Trans. Automat. Des., n. 108, p. 424-432. DOI: 10.1115/1.3260774.

ANTONESCU P. (1979) Book: Mecanisme, calculul structural şi cinematic, Editura IPB, Bucureşti.

CAO, W.; DING, H.; ZI, B.; CHEN, Z, (2013) New structural representation and digital-analysis platform for symmetrical parallel mechanisms. Int. J. Adv. Robotic Syst., n. 10, p. 243-255. http://cdn.intechopen.com/pdfs/44679.pdf

CHO, S.; AHN, K.; LEE, J. M. (2006) Efficiency of the planetary gear hybrid powertrain. SAGE Jo. Automobile Eng., n. 220, p. 1445-1454. DOI:

10.1243/09544070JAUTO176.

DEL CASTILLO, J. M. (2002) The analytical expression of the efficiency of planetary gear trains. Mech. Machine Theory, n. 37, p. 197-214. DOI: 10.1016/S0094114X(01)00077-5.

GARCIA, E.; JIMENEZ, M. A.; DE SANTOS, P. G.; ARMADA, M. (2007) The evolution of robotics research. IEEE Robot. Automat. Magazine, n. 14, p. 90-103. DOI: 10.1109/MRA.2007.339608.

LEE, B. J. (2013) Geometrical derivation of differential kinematics to calibrate model parameters of flexible manipulator. Int. J. Adv. Robot. Syst., n. 10, p. 106-115. DOI: $10.5772 / 55592$.

MARTIN, K. F. (1981) The efficiency of involute spur gears. ASME J. Mech. Des., n. 103, p. 160-169. DOI: 10.1115/1.3254855.

PELECUDI, C. H. R.; MAROŞ, D.; MERTICARU, V.; PANDREA, N.; SIMIONESCU, I. (1985) Mecanisme, Editura Didactică şi Pedagogică, Bucureşti.

PENNESTRI, E. E.; FREUDENSTEIN, F. F. (1993) The mechanical efficiency of epicyclic gear trains. ASME. J. Mech. Des., n. 115, p. 645-651. DOI:

10.1115/1.2919239.

PETRESCU, F. I. T.; PETRESCU, R. V. (2011) Trenuri Planetare. 1 Edn., CreateSpace Independent Publishing Platform, ISBN-10: 1468030418, p. 204.

PETRESCU, F. I. T. (2012) Teoria Mecanismelor: Curs si Aplicatii. 1st Edn.,

CreateSpace Independent Publishing Platform, ISBN-10: 1479293628, p. 304.

PETRESCU, FIT., 2019. About the nuclear particles' structure and dimensions.

Comp. Part. Mech. Volume 6, Issue 2, Pages 191-194.

https://doi.org/10.1007/s40571-018-0206-7

PETRESCU, R. V.; AVERSA, R.; APICELLA, A.; MIRSAYAR, M. M.; PETRESCU, F. I. T. (2016) About the Gear Efficiency to a Simple Planetary Train. American

Journal of Applied Sciences, v. 13, n. 12, p. 1428-1436. DOI:

10.3844/ajassp.2016.1428.1436. (2016)

PETRESCU, F. I. T.; PETRESCU, R. V. (2014a) High efficiency gear. Facta

Universitatis, Series: Mech. Eng., n. 12, p. 51-60.

PETRESCU, F. I. T.; PETRESCU, R. V. (2014b) High efficiency gears synthesis by avoid the interferences. Independent J. Manage. Product., n. 5, p. 275-298. 